\title{
SYNTHESIS OF COPPER AND MANGANESE COMPLEXES WITH METHIONINE AND TRYPTOPHAN: ANALYSIS BY ATOMIC ABSORPTION SPECTROPHOTOMETRY
}

\author{
AZKAAFINA HINDERSAH, HARMITA*, CATUR JATMIKA \\ Department of Pharmacy, Faculty of Pharmacy, Universitas Indonesia, Depok, 16424, Indonesia. Email: igakadeharmita@gmail.com
}

Received: 15 June 2018, Revised and Accepted: 20 October 2018

\begin{abstract}
Objective: In this study, we aimed to create complexes consisting of copper and manganese mineral elements and amino acids.

Methods: We determined the mineral element levels both bound and in their free state using atomic absorption spectrophotometry. The synthesized complexes were characterized using infrared spectrophotometry, while the free and bound mineral contents were separated using ion exchange chromatography.
\end{abstract}

Results: Our results demonstrated that the synthesis of such complexes was successful. The free mineral contents of the copper-methionine, coppertryptophan, and manganese-methionine complexes were $4.52,6.53$, and $0.056 \mathrm{mg} / \mathrm{kg}$, respectively, while the bound mineral contents of the coppermethionine, copper-tryptophan, manganese-methionine, and manganese-tryptophan complexes were 96.885, 114.974, 57.778, and 49.624 mg/kg, respectively.

Conclusion: The synthesis of copper and manganese complexes were successfully formed and analysis.

Keywords: Atomic absorption spectrophotometry, Copper, Infrared, Ion exchange chromatography column, Manganese, Methionine, Tryptophan.

(C) 2018 The Authors. Published by Innovare Academic Sciences Pvt Ltd. This is an open access article under the CC BY license (http://creativecommons. org/licenses/by/4. 0/) DOI: http://dx.doi.org/10.22159/ijap.2018.v10s1.23

\section{INTRODUCTION}

Mineral elements are required by the body in amounts ranging from $<1$ to $2500 \mathrm{mg} /$ day, depending on the type mineral. If a mineral deficiency occurs in the body, physiological processes involving enzymatic systems can be disrupted, while minerals in excessive amounts can effectively lead to poisoning. Thus, the concentration of mineral elements must be well regulated $[1,2]$. Copper and manganese are two essential minerals required by the body; however, in the free form, they cannot be absorbed or stored in the body to any significant degree compared with their bound forms [3].

Amino acids are organic compounds that can bind mineral elements. The binding between a mineral element and a hydrophobic amino acid serves to reduce the polarity of the mineral element, such that an increase in the lipophilicity of the bound mineral increases its ability to penetrate glycolipophilic membranes [4]. Complexes consisting of amino acids and minerals can be used as dietary supplements for humans. For example, complexes of copper and amino acids have been shown to benefit bone formation and the production of hemoglobin and red blood cells [5].

The synthesis of mineral complexes with amino acids is simple; one method has been reported by Tanila et al. [6] In this method, amino acids are first deprotonated by the addition of $0.33 \mathrm{~mL} \mathrm{NaOH}$ (30 followed by the addition of mineral salts [6]. The resulting complex is then characterized to determine if it was successfully synthesized. One common technique used in this process is infrared spectrophotometry, which compares the amino acid functional groups that are bound to the mineral elements. The presence of a wavelength shift further indicates that the complex has been successfully formed [7].

However, before determining the amount of bound and free mineral elements in the complex, it is necessary to first separate them. Current separation methods for this purpose include coprecipitation, absorption using resins, and separation with ion exchange resins, all of which serve to separate the mineral elements, in both their free and bound forms, from the organic compounds [8].

In this study, we synthesized a complex made of minerals and amino acids using a simple method. We then measured the free and bound mineral contents after separation by ion exchange chromatography using atomic absorption spectrophotometry (AAS). AAS is one of the analytical techniques used to measure the number of elements based on the amount of light energy they absorb from the light source.

\section{METHODS}

The chemicals used in this study were reagent grade or higher and included $1000 \mathrm{mg} / \mathrm{L}$ copper ion solution (Merck), 1,000 mg/L manganese ion solution (Merck), copper sulfate pentahydrate (Merck), manganese sulfate heptahydrate (Merck), methionine (CheilJedang, Bio Malaysia), tryptophan (CheilJedang, Indonesia), $\mathrm{KBr}$ (Merck), adsorber resin XAD-2 (Sigma-Aldrich), nitric acid (Merck), sodium hydroxide (Merck), perchloric acid (Merck), chloride acid (Merck), ethanol (Merck), methanol (Merck), acetone (Brataco), and Aquades (Brataco).

\section{Tools}

The instruments used in this study were an AA-6300 (Shimadzu) AAS, a hollow cathode lamp (copper and manganese), a Fourier transform infrared spectrophotometer (FTIR) (FTIR 8400; Shimadzu) equipped with a diffuse reflectance spectroscopy 8000 (Shimadzu), an oven, a hotplate, analytical scales, columns sized $15 \mathrm{~mm} \times 150 \mathrm{~mm}$, a desiccator, a refrigerator, Whatman filter paper $0.45 \mathrm{~mm}$, Whatman filter paper No. 42, volume pipettes, rubber balloons, and glassware.

\section{Preparation of standard solutions}

The standard solutions for use in the calibration curves of copper and manganese were prepared by diluting the copper and manganese master liquids $(1000 \mu \mathrm{g} / \mathrm{mL})$ to obtain a curve series with concentrations of 0 , $0.5,1.0,2.0,4.0$, and $8.0 \mu \mathrm{g} / \mathrm{mL}$ each for copper and manganese. The 
uptake was then measured by AAS at a wavelength of $324.8 \mathrm{~nm}$ for copper and $279.5 \mathrm{~nm}$ for manganese.

\section{Synthesis of amino metal complexes}

The complexes consisting of metals with amino acids were synthesized in two different ways:

- Method 1: A total of 0.002 moles of amino acids was dissolved in $10 \mathrm{~mL}$ of aquades at $40^{\circ} \mathrm{C}$, with constant stirring until completely dissolved. Then, up to $0.33 \mathrm{~mL}$ of $30 \%$, $\mathrm{NaOH}$ was added to the amino acid solution, with constant stirring for $3 \mathrm{~min}$. A total of 0.001 moles of the metal in its salt form was dissolved in $10 \mathrm{~mL}$ of aquades in different glass beakers and added to the amino acid solution, with constant stirring for $45 \mathrm{~min}$. The precipitate formed was then filtered using $0.45 \mathrm{~nm}$ Whatman filter paper and dried at room temperature. The sample was then stored in a desiccator until use. This method was used to prepare the coppermethionine, copper-tryptophan, and manganese-tryptophan complexes.

- Method 2: A total of 0.002 moles of amino acids was dissolved in $10 \mathrm{~mL}$ of aquades at $40^{\circ} \mathrm{C}$, with constant stirring until completely dissolved. A total of 0.001 moles of metal in its salt form was then dissolved in $5 \mathrm{~mL}$ of aquades in a different glass beaker and added to the methionine solution, with stirring for $2 \mathrm{~h}$. The solution was then evaporated to form crystals. This method was used to prepare the manganese-methionine complex.

\section{Identification of functional groups in synthesized complexes}

The complexes formed between the metals and amino acids were identified using a FTIR. A total of $2 \mathrm{mg}$ of the precipitated complex formed was weighed and mixed with $98 \mathrm{mg}$ of $\mathrm{KBr}$ powder, and then finely ground and homogenized using a mortar and pestle made of jade. The mixed powder was then inserted into the cup (disc) and inserted into the FTIR to obtain its absorption spectrum using a wave number between 400 and $4000 \mathrm{~cm}^{-1}$.

\section{Sample setup}

The bonded and free metals were separated using an adsorption column method, in which the metal bound to the amino acid is retained on the adsorbent, while the free metal form is dissolved. We used columns containing resins as adsorbents, with column sizes of $1.5 \mathrm{~cm} \times 15 \mathrm{~cm}$ [8]. First, we performed column conditioning where the resin was rinsed sequentially using methanol, $1 \mathrm{~mol}$ of HNO3 solution in acetone and aquadest [8]. The resulting synthesized precipitate was dissolved in aquades followed by incorporation into the column containing the resin. The first elution results represented the metal in its free form, while the copper metal that was bound to the amino acid was absorbed by the column. The first elution results were then assessed for its metal content using an AAS.

The destruction of the sample to determine the total metal content was performed by the wet destruction method. A total of $50 \mathrm{mg}$ of each of the synthesized compounds was added to $10 \mathrm{~mL}$ of nitric acid p.a. and $10 \mathrm{~mL}$ of perchloric acid p.a. and heated over a hotplate at $200^{\circ} \mathrm{C}$ until the yellow vapor was exhausted and replaced by a white vapor. The resulting solution was then filtered using Whatman filter paper No. 42 and put into a $50 \mathrm{~mL}$ measuring flask. Aquades was added to the flask to make up the volume to $50 \mathrm{~mL}$ and make it homogeneous. The results of the solution were then measured for the metal content using an AAS.

\section{Determination of the metal content}

The analysis conditions for the measurement of copper and manganese contents using AAS are shown in Table 1.

\section{RESULTS}

\section{Preparation of standard solutions}

The standard solution series for the copper and manganese calibration curves were obtained by diluting the master concentration $(1000 \mu \mathrm{g} / \mathrm{mL})$ to $0,0.5,1.0,2.0,4.0$, and $8.0 \mu \mathrm{g} / \mathrm{mL}$. The equation of the calibration curve obtained for copper was $y=0.0063 x+0.0014$, with a correlation coefficient value (r) equal to 0.99999 and the value of $\mathrm{V}_{\mathrm{x} 0}=0.255 \%$. The equation of the calibration curve obtained for manganese was $y=0.0382 x+0.0066$, with the value of the correlation coefficient ( $\mathrm{r}$ ) equal to 1 and the value of $\mathrm{V}_{\mathrm{x} 0}$ equal to $0.255 \%$.

\section{Synthesis of the amino metal complex}

In the formation of the copper-methionine (Fig. 1) and coppertryptophan complexes (Fig. 2), the results obtained consisted of fine blue purplish deposits, with yield values of each complex being $89.90 \%$ and $95.79 \%$, respectively. For the synthesis of the manganesemethionine (Fig. 3) and manganese-tryptophan (Fig. 4) complexes, fine sugars and ivory white crystals were obtained, with yield values of each complex being $92.15 \%$ and $83.83 \%$, respectively.

\section{IDENTIFICATION OF FUNCTIONAL GROUPS IN THE SYNTHESIZED COMPOUNDS}

The infrared spectra obtained for the copper-methionine complex showed the presence of $\mathrm{N}-\mathrm{H}$ groups at $3,238 \mathrm{~cm}^{-1}, \mathrm{C}=0$ groups

\section{Table 1: Analysis conditions of content determination}

\begin{tabular}{lll}
\hline Measurement & Mn & $\mathbf{C u}$ \\
\hline Wavelength & $279.5 \mathrm{~nm}$ & $324.8 \mathrm{~nm}$ \\
Slit wide & $0.2 \mathrm{~nm}$ & $0.7 \mathrm{~nm}$ \\
Lamp current low & $8 \mathrm{~mA}$ & $6 \mathrm{~mA}$ \\
Lamp current high & $0 \mathrm{~mA}$ & $0 \mathrm{~mA}$ \\
High burner & $7 \mathrm{~mm}$ & $7 \mathrm{~mm}$ \\
Acetylene gas flow rate & $2.0 \mathrm{~L} / \mathrm{min}$ & $1.8 \mathrm{~L} / \mathrm{min}$ \\
Airflow rate & $15.0 \mathrm{~L} / \mathrm{min}$ & $15.0 \mathrm{~L} / \mathrm{min}$ \\
\hline
\end{tabular}

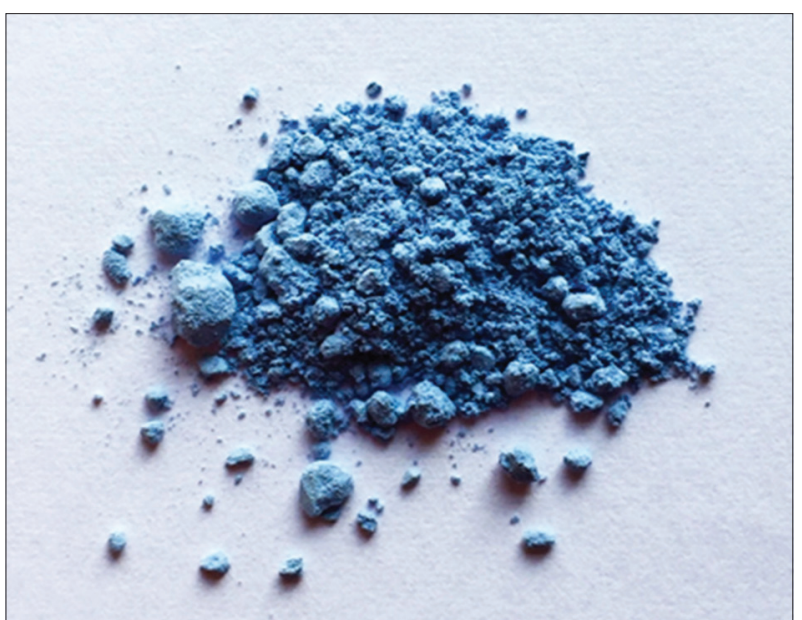

Fig. 1: Copper-methionine complex

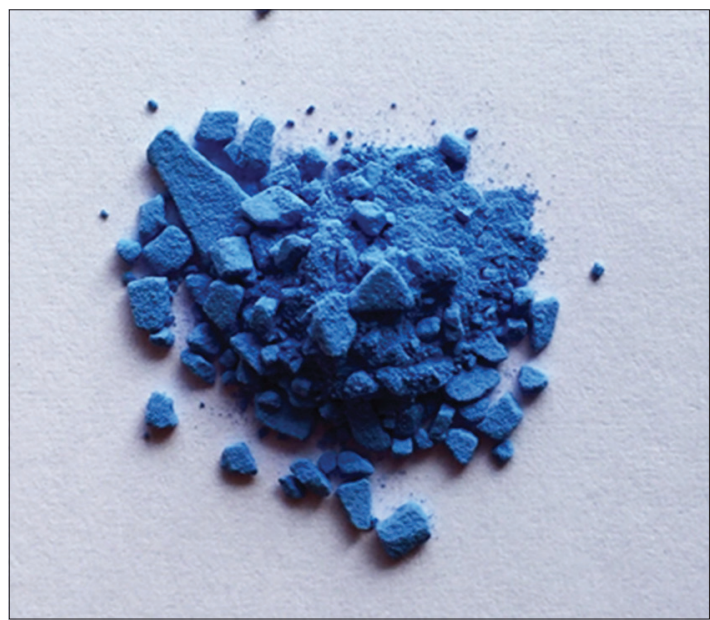

Fig. 2: Copper-tryptophan complex 
at $1616 \mathrm{~cm}^{-1}, \mathrm{C}-\mathrm{NH}$ groups at $1570 \mathrm{~cm}^{-1}$, and $\mathrm{C}-\mathrm{C}$ aliphatic at $1334 \mathrm{~cm}^{-1}$ (Fig. 5).

From the infrared spectrum of the copper-tryptophan complex, there was an $\mathrm{N}-\mathrm{H}$ group at $3269 \mathrm{~cm}^{-1}$, a C $=0$ group at $1626 \mathrm{~cm}^{-1}$, a C-NH group at $1570 \mathrm{~cm}^{-1}$, a C-H group at $1386 \mathrm{~cm}^{-1}$, an $\mathrm{O}-\mathrm{H}$ group at $3390 \mathrm{~cm}^{-1}$, and indoline groups at 740 and $1456 \mathrm{~cm}^{-1}$ (Fig. 6).

For the infrared spectrum of the manganese-methionine complex, there was an $\mathrm{O}-\mathrm{H}$ group at $3585 \mathrm{~cm}^{-1}$ and a $\mathrm{C}=0$ group at $1789 \mathrm{~cm}^{-1}$ with low intensity. The results of the manganese-methionine spectrum were then compared with the standard methionine spectrum shown in Fig. 7.

In the infrared spectrum of the manganese-tryptophan complex, there were $\mathrm{N}-\mathrm{H}$ groups at $3329 \mathrm{~cm}^{-1}$, a C= 0 group at $1627 \mathrm{~cm}^{-1}$, a C-NH group

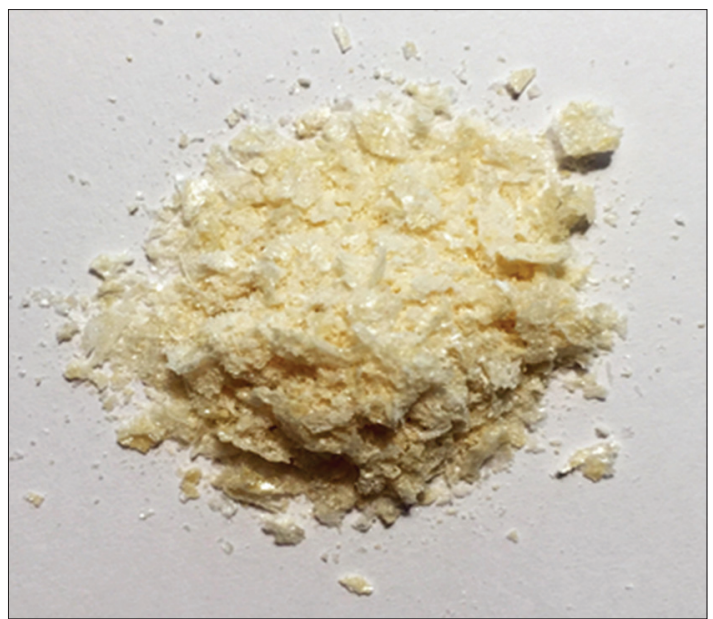

Fig. 3: Manganese-methionine complex

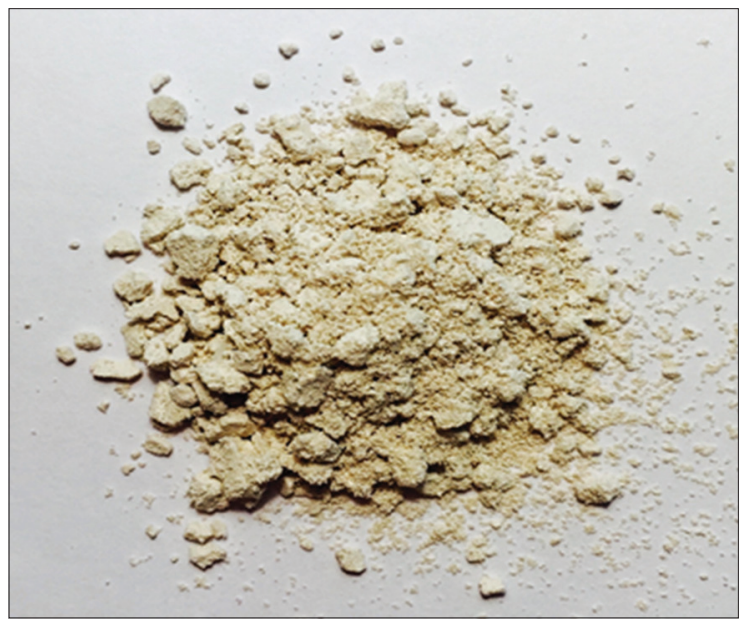

Fig. 4: Manganese-tryptophan complex at $1579 \mathrm{~cm}^{-1}$, a C-H group at $1458 \mathrm{~cm}^{-1}$, an $0-\mathrm{H}$ group at $3419 \mathrm{~cm}^{-1}$, and indoline groups at $749 \mathrm{~cm}^{-1}$, and $1374 \mathrm{~cm}^{-1}$ (Table 2 and Fig. 8).

\section{Sample setup}

Free and bound metals were separated using an ion chromatography column with a column diameter of $1.5 \mathrm{~cm}$ and a height of $15 \mathrm{~cm}$. The stationary phase used was a resin of $10 \mathrm{~g}$ with a column height of $5 \mathrm{~cm}$. The results showed that the free metal eluted for $10 \mathrm{~min}$ until $10 \mathrm{~mL}$ of the result was obtained; the elution result was a clear solution and no precipitate was observed.

To determine the total metal content, the synthesized compounds previously obtained were detected by means of wet destruction by mixing nitric acid and perchloric acid p.a. into $50 \mathrm{mg}$ of the complex compounds followed by destruction. The results of the destruction of the complex compounds yielded a clear, bright blue solution for the copper-methionine complex and a yellow-chocolate color for the copper-tryptophan, manganese-methionine, and manganesetryptophan complexes.

\section{Content determination}

Based on our results, the free metal content of the complex compounds separated by ion column chromatography showed a low metal content of $4.526,6.532$, and $0.056 \mathrm{mg} / \mathrm{kg}$ for the copper-tryptophan, coppermethionine, and manganese-methionine complexes, respectively. The total metal content of the destructed complexes was 119.500, $281.792,57.767$, and $49.684 \mathrm{mg} / \mathrm{kg}$ for the copper-tryptophan, coppermethionine, manganese-tryptophan, and manganese-methionine complexes, respectively. The yield of the bonded metal content for the copper-tryptophan, copper-methionine, manganese-tryptophan, and manganese-methionine complexes was 96.885, 114.974, 49.624, and $57.778 \mathrm{mg} / \mathrm{kg}$, respectively (Table 3 and 4 ).

\section{DISCUSSION}

In preparing the standard solutions for the calibration curves, the results of linearity calculation values indicated that the calibration curve equation lines for both copper and manganese metals were eligible and linearly expressed $[9,10]$.

In the formation of metal complexes with the amino acids, the addition of $30 \% \mathrm{NaOH}$ served to deprotonate the $\mathrm{H}$ element in the carboxylic group of the amino acid so that the metal in its salt form could bind to the carboxylic group in the amino acid, thus forming a complex compound [6]. Complex formation was carried out at $40^{\circ} \mathrm{C}$ due to the amino acids methionine and tryptophan, which are soluble in hot conditions.

The characterization of complex formation, performed by infrared spectrophotometry, demonstrated the resulting shift in wave number, as seen from the comparison of the infrared spectrum of the amino acids and the resulting complex spectrum. The methionine $\mathrm{O}-\mathrm{H}$ carboxylic group at $3,157 \mathrm{~cm}^{-1}$, with wide and medium intensities, was not found in the synthesized compound. This indicates that there was a deprotonation of the $\mathrm{O}-\mathrm{H}$ group, where the $\mathrm{H}$ element is removed and is replaced by $\mathrm{Cu}$. Then, the $\mathrm{C}=0$ group of the synthesized compound undergoes a shift to a higher wave number at $1616 \mathrm{~cm}^{-1}$; whereas in

Table 2: Data of the wave number $\left(\mathrm{cm}^{-1}\right)$ of the amino acid metal complex functional groups

\begin{tabular}{|c|c|c|c|c|c|c|}
\hline Functional group & Copper-methionine & Copper-tryptophan & Manganese-methionine & Manganese-tryptophan & Methionine & tryptophan \\
\hline $\mathrm{N}-\mathrm{H}$ & 3238 & 3269 & & 3269 & 3157 & $\begin{array}{l}3078 \\
3028\end{array}$ \\
\hline $\mathrm{O}-\mathrm{H}$ & & 3390 & 3585 & 3419 & & 3404 \\
\hline $\mathrm{C}=\mathrm{O}$ & 1616 & 1626 & 1589 & 1627 & 1583 & 1666 \\
\hline $\mathrm{C}-\mathrm{NH}$ & 1570 & 1570 & & 1579 & 1512 & 1591 \\
\hline $\mathrm{C}-\mathrm{C}$ & 1334 & & & & 1352 & \\
\hline $\mathrm{C}-\mathrm{H}$ & & 1386 & & 1458 & 1410 & 1415 \\
\hline $\mathrm{CH}_{2} \mathrm{~S}-\mathrm{CH}_{3} \mathrm{~S}$ & 2915 & & & & & \\
\hline \multirow[t]{2}{*}{ Indoline } & & 740 & & 749 & & 744 \\
\hline & & 1456 & & 1374 & & 1458 \\
\hline
\end{tabular}


Table 3: Results of total metal content determination (free and bound)

\begin{tabular}{|c|c|c|c|c|c|c|}
\hline Compounds & BM & Weight (g) & Concentration $(\mu \mathrm{g} / \mathrm{mL})$ & Total volume (mL) & Dilution factor & Total metal content $(\mathrm{mg} / \mathrm{kg})$ \\
\hline Copper-tryptophan & 459.55 & 0.0500 & 1.1950 & 50 & 100 & 119.500 \\
\hline Copper-methionine & 359.55 & 0.0501 & 1.0362 & 50 & 100 & 103.415 \\
\hline Manganese-tryptophan & 450.94 & 0.0504 & 0.5823 & 50 & 100 & 57.778 \\
\hline Manganese-methionine & 350.94 & 0.0507 & 0.5038 & 50 & 100 & 49.684 \\
\hline
\end{tabular}

Table 4: Results of free metal content determination (column yield)

\begin{tabular}{lllllll}
\hline Compounds & BM & Weight $(\mathbf{g})$ & Concentration $(\boldsymbol{\mu g} / \mathbf{m L})$ & Total volume $(\mathbf{m L})$ & Dilution factor & Total metal content (mg/kg) \\
\hline Copper-tryptophan & 459.55 & 0.0499 & 2.2587 & 10 & 10 & 4.526 \\
Copper-methionine & 359.55 & 0.0494 & 3.2271 & 10 & 10 & 1 \\
Manganese-tryptophan & 450.94 & 0.0507 & -0.1138 & 10 & 1 & Not detected \\
Manganese-methionine & 350.94 & 0.0506 & 0.2839 & 10 & 0.06 \\
\hline
\end{tabular}

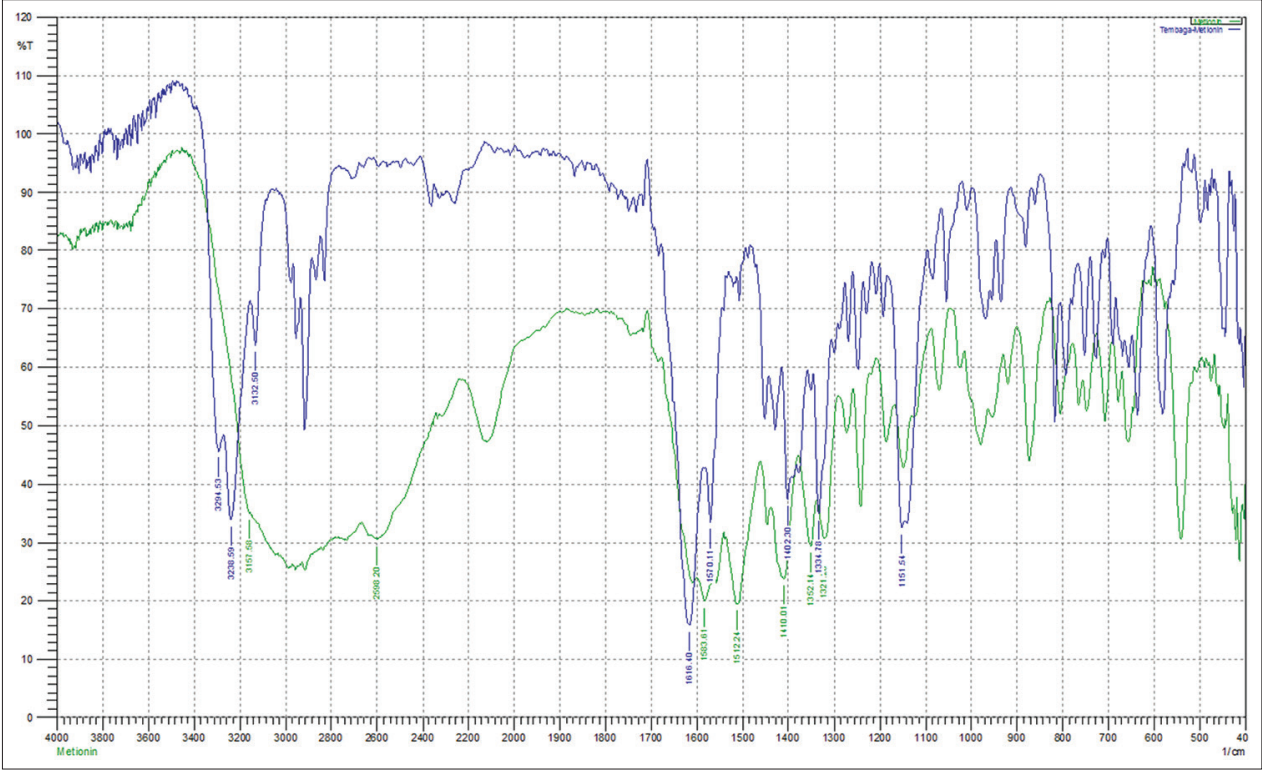

Fig. 5: Overlay spectrum of copper-methionine, with methionine in blue denoting the spectrum of the complex and green representing the methionine spectrum

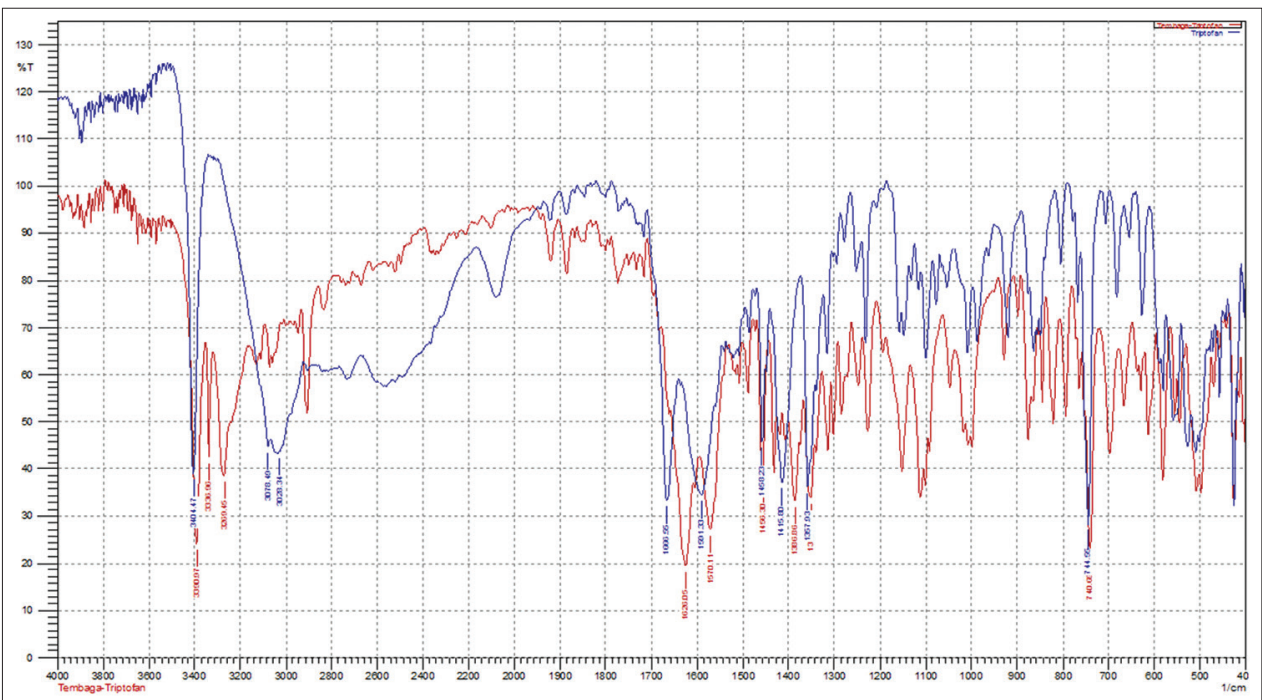

Fig. 6: Overlay spectrum of the copper-tryptophan complex, with tryptophan in red indicating the spectrum of the complex and purple representing the spectrum of tryptophan 


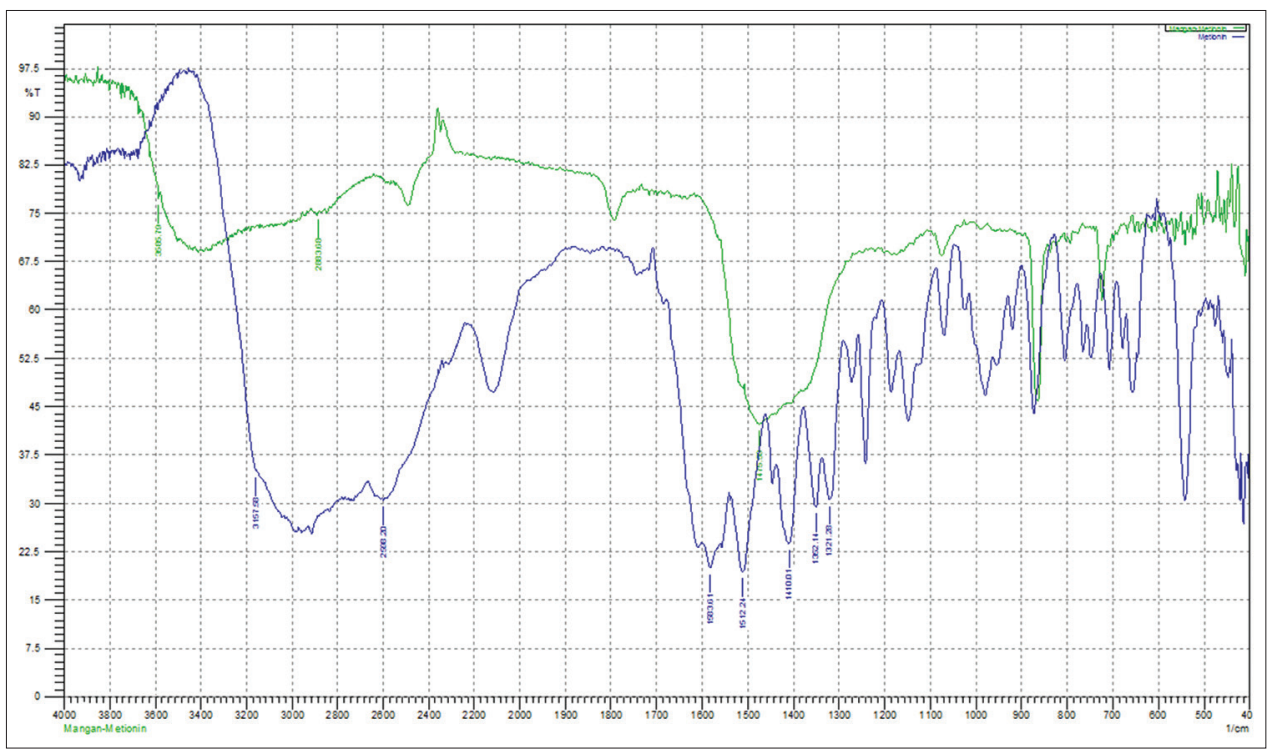

Fig. 7: Overlay spectrum of the manganese-methionine complex, with methionine in green indicating the spectrum of the manganesemethionine complex and blue representing the methionine spectrum

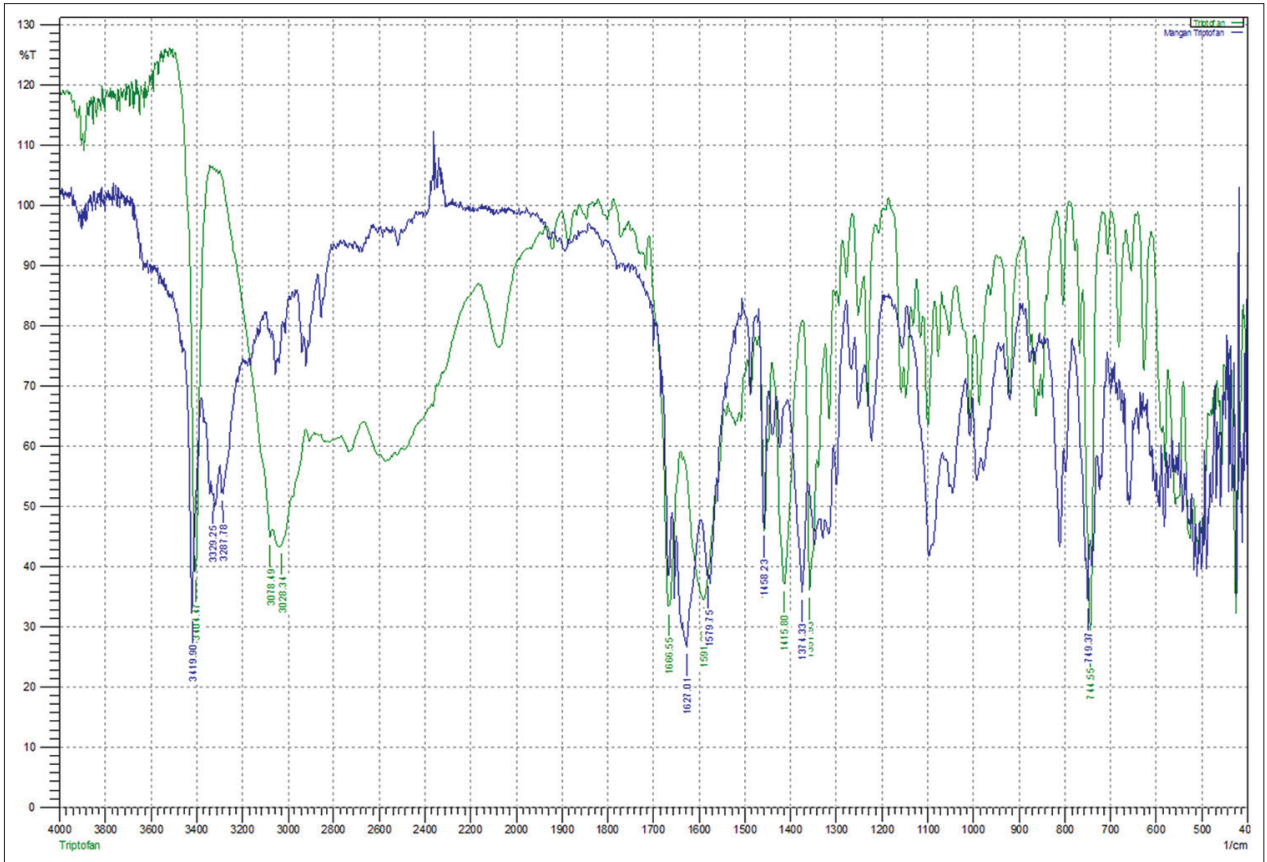

Fig. 8: Overlay spectrum of the manganese-tryptophan complex, with tryptophan in green indicating the spectrum of the manganesetryptophan complex and purple representing the tryptophan spectrum

methionine, the $\mathrm{C}=0$ group is at $1,583 \mathrm{~cm}^{-1}$, indicating that the covalently bonded $\mathrm{Cu}$ molecule is in the $\mathrm{C}=\mathrm{O}[6]$. In standard tryptophan, the $\mathrm{N}-\mathrm{H}$ group is at $3078 \mathrm{~cm}^{-1}$, but in the copper-tryptophan complex, the $\mathrm{N}-\mathrm{H}$ group shifts to a higher wave number at $3269 \mathrm{~cm}^{-1}$. This indicates that there was a strong interaction between the $\mathrm{N}-\mathrm{H}$ group and the $\mathrm{Cu}$ metal. As in the copper-methionine complex, the $\mathrm{C}=0$ group in the coppertryptophan complex also appeared to undergo a shift in the wave number. In the copper-tryptophan complex, the $\mathrm{C}=0$ group undergoes a shift to a lower wave number at $1626 \mathrm{~cm}^{-1}$, while the $\mathrm{C}=0$ group in tryptophan is present at $1666 \mathrm{~cm}^{-1}$. This is because the strength of the $\mathrm{C}=\mathrm{O}$ bond in the copper-tryptophan complex is weakened by the presence of the bound element of $\mathrm{Cu}$.

In determining the metal content of the complex compound, the results of the synthesis by two treatments were demonstrated. To determine the content of the metal in its free form, the compound of the synthesis product was first separated by the chromatography column method. In the chromatography column, a stationary phase of resin, which was previously conditioned, was used. The purpose of this conditioning is to keep the surface of the resin positively charged; thus, free positively charged metals are not attached to the resin and, rather, come out in the eluent. The compound is then dissolved in aquades due to amino acid compounds that are insoluble in aquades. The resulting compound of the synthesized complex is also not soluble in aquades, so the expected soluble compound in aquades is only the metal in its free form.

In determining the total metal content in the complex compounds, the complexes are first destroyed. Destruction is performed so that the organometallic bond breaks into free inorganic ions. The method of destruction we used in this study was wet destruction, which 
represents a sample reshuffle with strong acids either singly or mixed followed by oxidation by means of an oxidizing agent [11]. In this study, the oxidizing agent added to the complex was concentrated nitric acid and perchloric acid. This is due to the addition of the two larval acids, with the destruction of the complex compounds formed more quickly. The resulting solution is clear, with no sediment. The free metal and total metal contents were determined using AAS. In the column separation sample, the uptake obtained for the manganese-methionine and manganese-tryptophan complexes was within the range of the calibration curve used. However, for the copper-methionine and copper-tryptophan complexes, they were above the range of the calibration curve used, and the direct destruction resulted in all the uptake of the complex solutions being above the range of the calibration curves used. Thus, dilution to the absorption of the sample was present in the range of the calibration curve. Dilutions up to $2 \times$ were prepared for the destruction and $1 \times$ samples for the column separation for the copper-methionine and copper-tryptophan complexes. The dilution of the resulting sample after destruction was greater than the dilution of the column separation sample, wherein the metal concentration in the resulting sample after destruction is believed to be greater. In determining the manganese-tryptophan complexes separated by ion exchange chromatography, our results indicated that the uptake was below the calibration curve. Our results also demonstrated that there was no free metal content in the tryptophan-manganese complex. The difference in levels between the first streamed compound into column chromatography and the directly detonated compound shows that the ion column chromatography method can be used to separate the free metal from the amino acid metal complexes.

\section{CONCLUSION}

Based on our results, the synthesis of copper with methionine and copper with tryptophan resulted in the formation of purplish blue and blue complexes, respectively. The synthesis of manganese with methionine and manganese with tryptophan resulted in the formation of ivory white crystals and a fine, ivory white complex, respectively. The metal content bound in the copper-methionine, copper-tryptophan, manganese-methionine, and manganese-tryptophan complexes was $96.885,114.974,57.778$, and $49.624 \mathrm{mg} / \mathrm{kg}$, respectively. The free metal content of the copper-methionine, copper-tryptophan, and manganese-methionine complexes was $4.52,6.53$, and $0.056 \mathrm{mg} / \mathrm{kg}$, respectively. No free metal content was detectable in the manganesetryptophan complex.

\section{CONFLICTS OF INTEREST}

All authors have none to declare.

\section{REFERENCES}

1. Arifin Z. Some elements of micro essential minerals in biological systems and methods of analysis. Indones J Agric 2008;27:99-101.

2. Soetan KO, Olaiya CO, Oyewole OE. The importance of mineral elements for humans, domestic animals and plants: A review. Afr J Food Sci 2010;4:200-22.

3. Pal DT, Gowda NK, Prasad CS, Amarnath R, Bharadwaj U, Suresh Babu G, et al. Effect of copper-and zinc-methionine supplementation on bioavailability, mineral status and tissue concentrations of copper and zinc in ewes. J Trace Elem Med Biol 2010;24:89-94.

4. Temitayo A, Isaac O, Olugbenga A. Structural and antimicrobial studies of cooerdination compounds of phenylalanine and glycine. Int J Chem 2012;4:49.

5. Puritan's Pride. Available from: http://www.puritan.com/mineralproducts-036/copper-chelate-2-mg-001330. [Last accessed on 2016 Oct 19].

6. Tanila A, Marcu A, Rusu D, Rusu M, David L. Spectroscopic studies of some Copper(II) complexes with amino acids. J Mol Struct 2006;834:364-8.

7. Mamun MA, Ahmed O, Bakshi PK, Ehsan MQ. Synthesis and spectroscopic, magnetic, and cyclic voltammetric characterization of some metal complexes of methionine: $\left[\left(\mathrm{C}_{5} \mathrm{H}_{10} \mathrm{NO}_{2} \mathrm{~S}\right)_{2} \mathrm{M}^{\mathrm{II}}\right]$; = Mn(II), $\mathrm{Co}(\mathrm{II}), \mathrm{Ni}(\mathrm{II}), \mathrm{Cu}(\mathrm{II}), \mathrm{Zn}(\mathrm{II}), \mathrm{Cd}(\mathrm{II})$, and $\mathrm{Hg}(\mathrm{II})$. J Saudi Chem Soc 2009; 14:23-7.

8. Tokalioglu S, Kartal S, Elci L. Speciation and determination of heavy metals in lake waters by atomic absorption spectrometry after sorption on amberlite XAD-16 resin. Anal Sci 2000;16:49-53.

9. Chae YS, Vacik JP, Shelver WH. Determination of copper and manganese in Vitamin-mineral tablets by atomic absorption spectrophotometry. J Pharm Sci 1973;62:1838-41.

10. Batista ÉF, Augusto Ados S, Pereira-Filho ER. Chemometric evaluation of $\mathrm{Cd}, \mathrm{Co}, \mathrm{Cr}, \mathrm{Cu}, \mathrm{Ni}$ (inductively coupled plasma optical emission spectrometry) and $\mathrm{Pb}$ (graphite furnace atomic absorption spectrometry) concentrations in lipstick samples intended to be used by adults and children. Talanta 2016;150:206-12.

11. Raimon J. Comparison of Methods of Wet and Dry Destruction by Spectrophotometry. Yogyakarta: Santika; 1993. 